
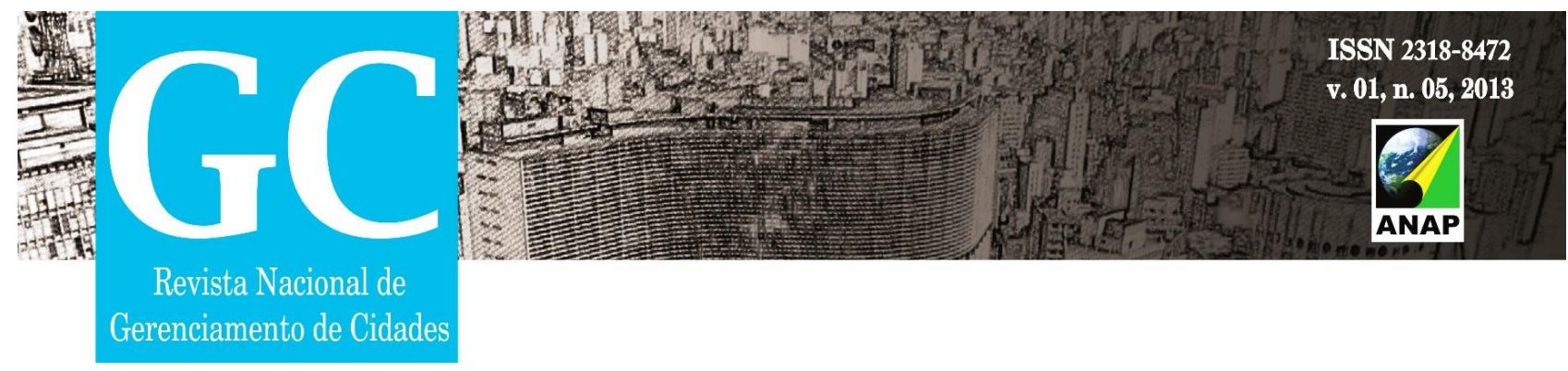

Titulo do Trabalho

\title{
A IMPORTÂNCIA DAS COOPERATIVAS DE MATERIAIS RECICLÁVEIS: UM BREVE RELATO DA EXPERIÊNCIA DO MUNICÍPIO DE SERRA TALHADA - PE
}

Nome do Autor (a) Principal

Felipe Luiz Lima de Paulo

Nome (s) do Coautor (a) (s)

Cibele Ferreira dos Santos; Maria Natiane da Silva

Instituição ou Empresa

Universidade Federal Rural de Pernambuco - Unidade Acadêmica de Serra Talhada

Instituição (s) de Fomento

Pró-Reitoria de Atividade de Extensão - PRAE (Universidade Federal Rural de Pernambuco)

E-mail de contato

felipe@uast.ufrpe.br

RESUMO: Os problemas decorrentes das questões ambientais afetam diretamente a população, e o maior problema encontrado é o excesso residual que é descartado na natureza que em sua maioria, são descartáveis, tendo assim uma vida útil curta. A criação de cooperativas vem sendo uma solução interessante para diminuir os prejuízos causados pelo elevado índice de consumo. No município de Serra Talhada - PE possui uma cooperativa, onde gera emprego e renda pela comercialização dos recicláveis, diminuindo o desperdício. Dessa forma, o presente trabalho tem como objetivo relatar a importância da experiência da implantação de uma cooperativa de materiais recicláveis no município de Serra Talhada - PE no tratamento de resíduos sólidos. Para elaboração desse trabalho foram coletados dados na Cooperativa de Catadores de Resíduos 

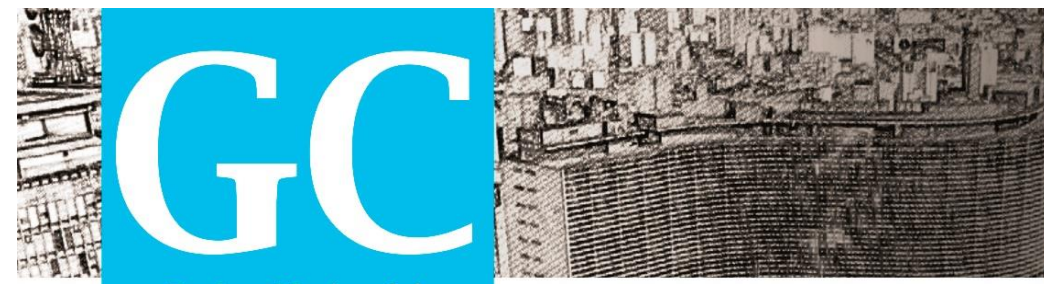

Revista Nacional de

Gerenciamento de Cidades

Recicláveis de Serra Talhada - Coopecamarest e no Lixão. Ao final, observou-se que a implantação de uma cooperativa na cidade de Serra talhada contribuiu positivamente com o equilíbrio para o meio ambiente e dignidade para as pessoas que vivem desses recursos.

Palavras chave: Resíduos Sólidos. Cooperativas. Reciclagem

\section{INTRODUÇÃO}

Atualmente está ocorrendo um visível declínio em relação à qualidade de vida e um dos principais motivos é o aumento das áreas urbanas que tem contribuído para crescimento de impactos ambiental. Os problemas decorrentes das questões ambientais afetam diretamente a população, e o maior problema encontrado é o excesso residual que é descartado na natureza que em sua maioria, são descartáveis, tendo assim uma vida útil curta. Nos últimos 30 anos, o Brasil mudou muito e o seu lixo também. O crescimento acelerado das cidades e, ao mesmo tempo, a mudança no consumo dos cidadãos, vem gerando um lixo muito diferente daquele que as cidades produziam anteriormente. $O$ lixo atual é diferente em quantidade, qualidade, volume e composição (CBS PREVIDÊNCIA, 2013).

Esse problema que a cada dia está visível perante a população e pode ser resolvido parcialmente por uma simples coleta seletiva e consequentemente pela reciclagem, evitando assim um extenso número de materiais, não renováveis, que são eliminados na natureza.

A criação de cooperativas está sendo a priori a solução mais adequada para diminuir os prejuízos causados pelo elevado índice de consumo, em algumas cidades. $\mathrm{Na}$ Serra Talhada - PE possui uma cooperativa, onde gera emprego e renda pela comercialização dos recicláveis, diminuindo o desperdício já que possibilita a reciclagem de materiais que iriam para o lixo, ajuda a diminui os custos da produção, com o aproveitamento de recicláveis pelas indústrias, diminui a poluição do solo, da água e do ar. Demostrando assim a importância de criações de cooperativas desse tipo para 

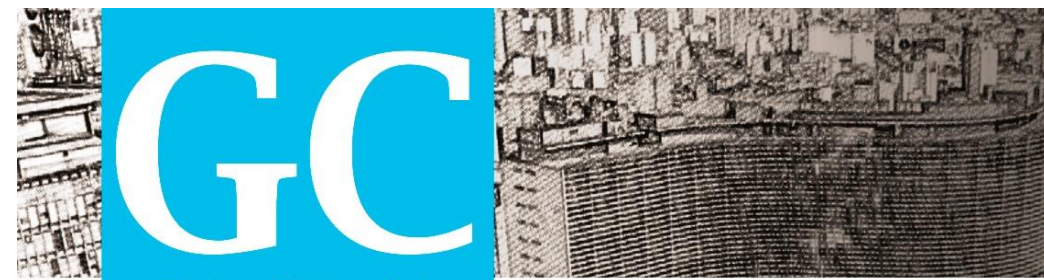

Revista Nacional de

Gerenciamento de Cidades

população. A criação de associações e cooperativas de catadores de lixo representa a alternativa de saída do homem dos lixões e o resgate da sua condição de cidadão, com direito a benefícios sociais, educação para os filhos, autonomia administrativa e possibilidade de ascensão social (FADINI e FADINI, 2001).

O presente trabalho tem como objetivo relatar a importância da experiência da implantação de uma cooperativa de materiais recicláveis no município de Serra Talhada PE no tratamento de resíduos sólidos.

\section{OBJETIVO GERAL}

O presente trabalho tem como objetivo relatar a importância da experiência da implantação de uma cooperativa de materiais recicláveis no município de Serra Talhada PE no tratamento de resíduos sólidos.

\section{OBJETIVOS ESPECÍFICOS}

$\checkmark$ Apresentar as duas realidades ambientais no tratamento de resíduos sólidos no município de Serra Talhada - PE (lixão e cooperativa de materiais recicláveis)

$\checkmark$ Expor as duas realidades sociais dos catadores de materiais recicláveis no município de Serra Talhada - PE (lixão e cooperativa de materiais recicláveis)

$\checkmark$ Exibir as duas realidades econômicas dos catadores de materiais recicláveis no município de Serra Talhada - PE (lixão e cooperativa de materiais recicláveis)

\section{METODOLOGIA}

Para elaboração desse trabalho foram coletados dados em uma visita técnica feita na Associação de Catadores de Resíduos Recicláveis de Serra Talhada a Coopecamarest (Cooperativa de Catadores de Materiais Recicláveis de Serra Talhada) e 

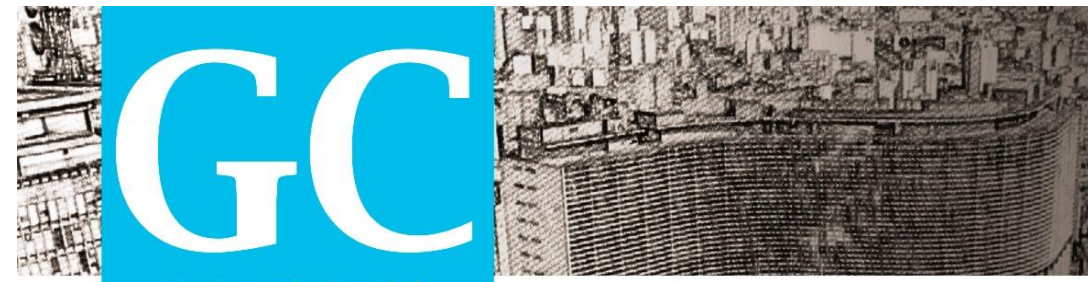

Revista Nacional de

Gerenciamento de Cidades

ao Lixão, por meio do curso de extensão "Capacitação em ICMS Socioambiental para Gestores Ambientais em Municípios do Sertão do Pajeú" que contou com apoio financeiro da Pró-Reitoria de Atividade de Extensão - PRAE da Universidade Federal Rural de Pernambuco, onde foi possível adquirir material sobre o assunto em questão.

\section{RESULTADO (S)}

No município de Serra Talhada - PE existe uma iniciativa de criação de Cooperativa de Catadores de Resíduos Recicláveis, que faz o tratamento adequado dos resíduos sólidos por meio da venda do material que pode ser reaproveitado pelas usinas. Já foram retiradas do Lixão cerca de 20 famílias que agora além de contribuir para o meio ambiente equilibrado, possui dignidade e respeito perante a sociedade, pois agora possui o reconhecimento social, além da garantia da sobrevivência com a remuneração de seu trabalho. Já no lixão de Serra Talhada, próximo a PE 390, que liga Serra ao município de Floresta, moram cerca de 60 pessoas que sobrevivem do lixo, mas que atualmente já receberam a proposta de trabalharem na Coopecamarest. De acordo com dados obtidos recentemente na Coopecamarest, foi possível observar que a mesma possui 23 integrantes, todos ex-catadores de lixo, trabalhando a cerca dois anos, promovendo coleta seletiva em algumas localidades na cidade com o apoio do Itep (Instituto de Tecnologia de Pernambuco).

O terreno que a Coopecamarest utiliza está localizado no bairro da Borborema. Há no local uma prensa hidráulica para compactar o material recolhido.

O fato é que as prefeituras têm até agosto de 2014 para acabar com todos os seus lixões conforme a Lei 12.305, que instituiu a Política Nacional de Resíduos Sólidos.

Ao final, foi possível observar as duas realidades distintas, uma da cooperativa (fig.1) onde há um tratamento adequado dos resíduos, e outra do lixão (fig.2) onde são depositados de forma inadequada todo tipo de descarte da sociedade. 


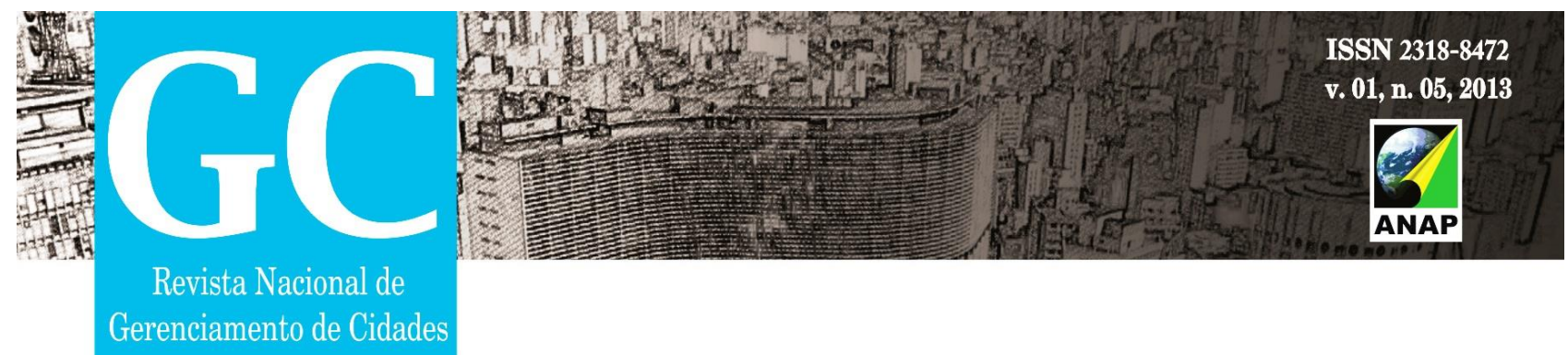

Figura 1 - Cooperativa de Materiais Recicláveis

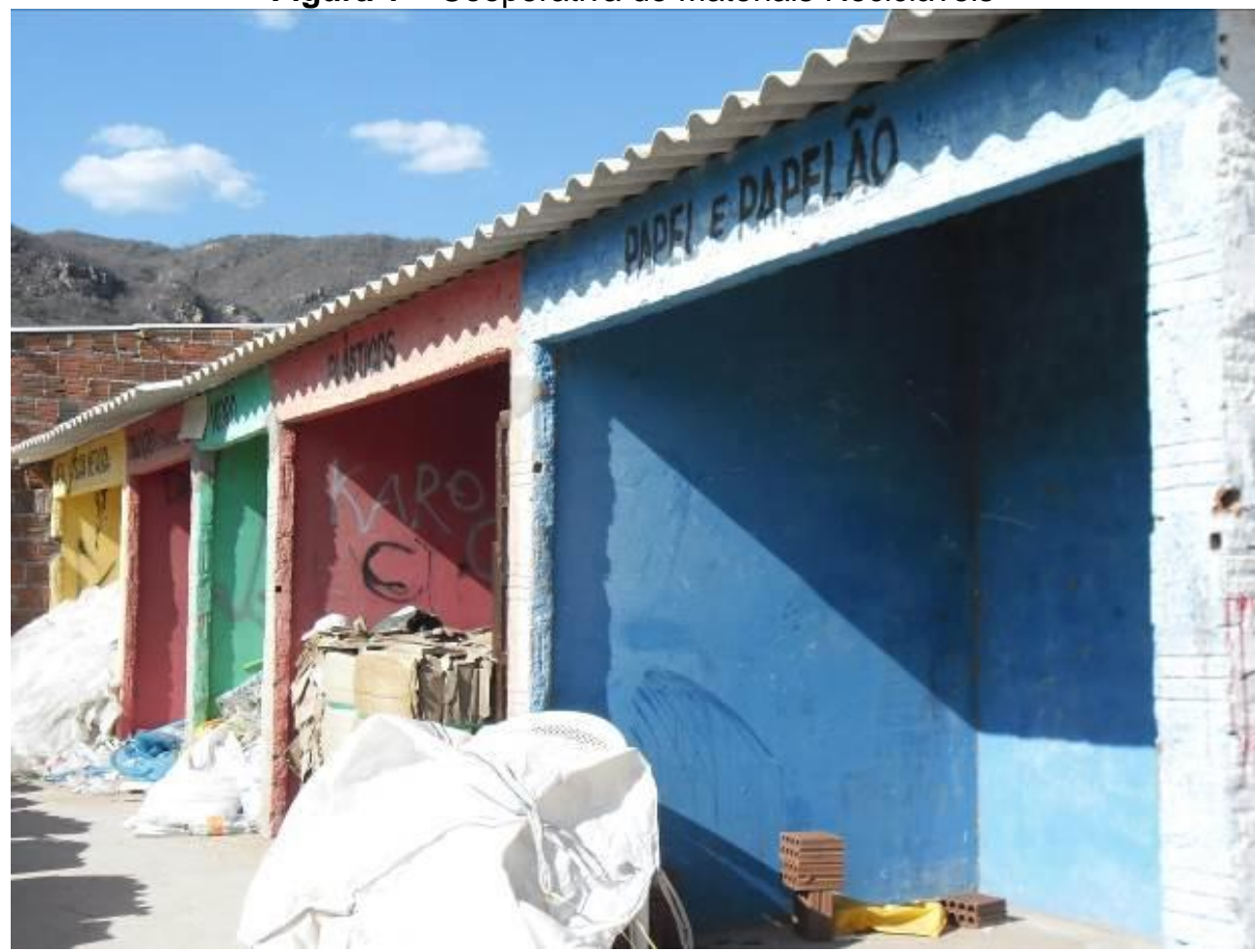

Fonte: os autores

Figura 2 - Lixão de Serra Talhada - PE

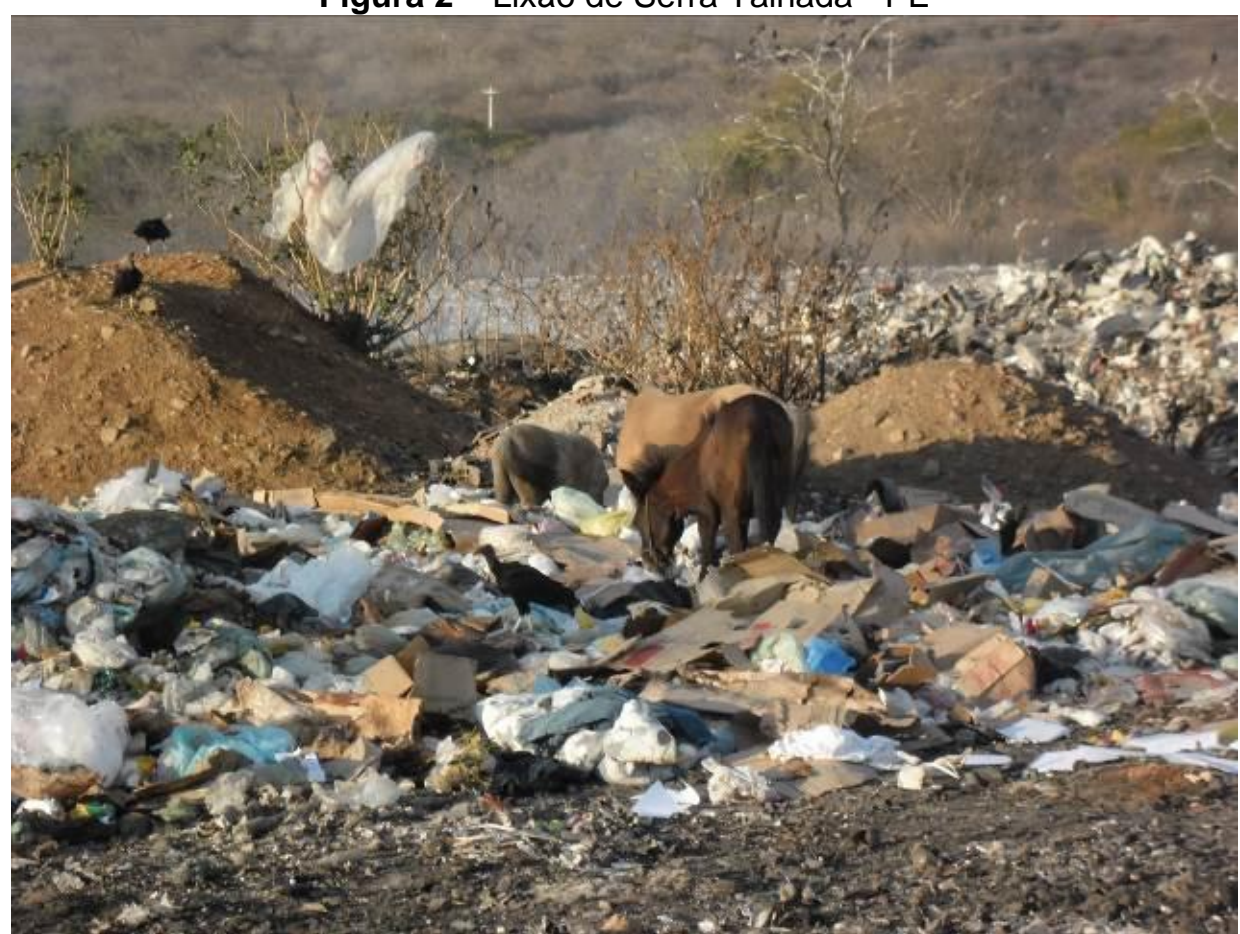

Fonte: os autores 

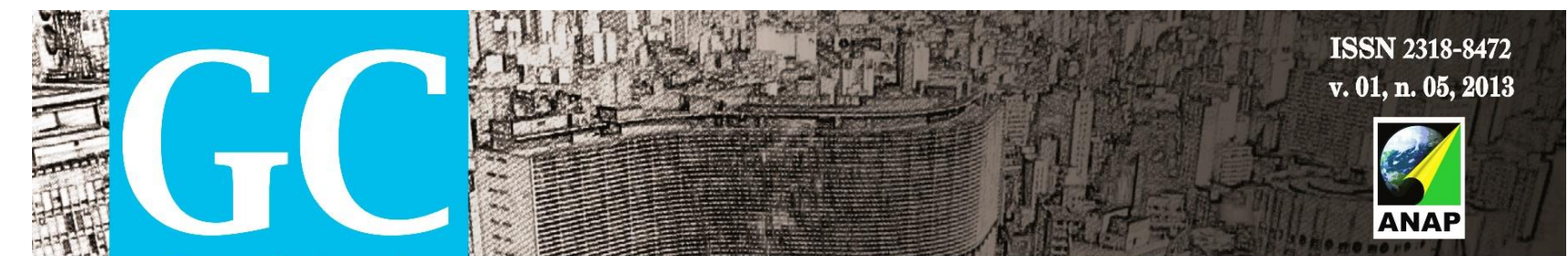

Revista Nacional de

Gerenciamento de Cidades

\section{CONSIDERAÇÕES FINAIS}

A implantação de uma cooperativa na cidade de Serra talhada contribuiu positivamente com o equilíbrio para o meio ambiente, dignidade para as pessoas que vivem desses recursos e respeitos perante a sociedade, garantindo assim reconhecimento social.

\section{REFERÊNCIAS}

CBS Previdência. Coleta seletiva de lixo. Disponível em < http://www.cbsprev.com.br/web/images/Coleta Seletiva de lixo.pdf.> Acesso em 11 de abril de 2013.

FADINI, P. S. ; FADINI, A. A. B. . Lixo: Desafios e Compromissos. Química Nova na Escola (Impresso), v. 1, p. 9-18, 2001 